\section{The future of in-patient child and adolescent mental health services ${ }^{\dagger}$}

SIMON G. GOWERS and ANDREW J. COTGROVE

Although the majority of children with mental health problems are treated in community services, a comprehensive child and adolescent mental health service (CAMHS) needs access to highly specialised provision including in-patient facilities. The notion of a tiered model of service, starting with resources provided in primary care (tier 1) through community CAMHS (tiers 2 and 3 ) and culminating in specialised services (tier 4), as proposed by the Health Advisory Service (1995), has been widely adopted by the Department of Health. In the absence of central planning and a coordinated commissioning structure, the development of in-patient services in England and Wales has been haphazard. This contrasts with the situation in general adult psychiatry in which local 'catchment area' beds are commissioned by primary care trusts for a local population. The ad hoc development of in-patient CAMHS has led to patchy provision for patients and their families and frustration among adult psychiatric colleagues, particularly when there is confusion about available resources and when young people are admitted as a consequence to adult beds. A lack of monitoring has led to a situation in which little is known about the precise number, distribution and function of these services, hence the Department of Health's decision to commission the National Inpatient Child and Adolescent Psychiatry Study (NICAPS). This study is a timely audit survey mapping out the provision of services for different populations. It is hard to believe that an equivalent lack of knowledge could exist about other highly specialised areas of the National Health Service (NHS).

\section{THE CONTRIBUTION FROM NICAPS}

The report by O'Herlihy et al (2003, this issue), the first peer-reviewed publication

†See pp. 547-55I, this issue. from NICAPS, is a descriptive paper without complicated analyses - see O'Herlihy et al (2001) for further details. However, the authors attempt to draw a number of conclusions in their discussion, mainly focused on a perceived need for more coherent development and provision, which they argue should be based on a national plan. What should we make of these findings, and how are they likely to be interpreted by health service commissioners?

The methods employed in the study are of interest. The authors felt the need to define a 'unit'; although the definition appears to have validity and is probably reliable, the need for definition demonstrates the researchers' belief that they would find variability in service style and function.

The study's first main outcome is that 80 units were identified, providing 900 beds. Can we judge whether this finding is good, bad or indifferent? There are several variables to consider: the epidemiology of mental health problems in children and adolescents, comparisons with other developed countries, the views of referring CAMHS, and evidence of inappropriate admissions elsewhere. The authors tell us that the bed numbers equate to a mean of 7.1 per 100000 population aged 18 years and under. If we take $7.1 \%$ as a conservative estimate of the prevalence of mental health problems in this population, this would suggest that 1 in 1000 children with a mental health problem could be admitted to an in-patient unit at any time. This does not appear to be a high level of provision, and it is one that is lower than in North America and much of Europe. Community CAMHS teams tend to complain more of the difficulty of accessing a bed when required, rather than of overprovision. One regional adolescent service has identified that the principal requirement of referrers from six disciplines was prompt access to in-patient beds (Gowers et al, 1991). There are also reports that significant numbers of young people are increasingly being admitted inappropriately to other medical services (chiefly paediatric or adult beds) in Wales (Duthie, 2001) and the north-west of England (Gowers et al, 2001). In both cases this finding was thought likely to be due to shortages of dedicated child and adolescent psychiatric beds. These independent findings support the suggestion that the uneven distribution of beds (a quarter as many in Wales as in the south-east of England) is indicative of a shortage in many parts of the country rather than an overprovision in the south-east. A recent report by the Royal College of Psychiatrists (2002) stressed the dangers of inappropriate admissions to adult beds, but we seem further than ever from achieving access to specialist beds when needed.

It is difficult to know what conclusion to draw from the finding that more than a quarter of beds in the study were managed by the independent sector. Clearly provision would be even more meagre without these beds. It would suggest that private hospital providers believe they have spotted a niche market, with a minimum of competition. There is currently no good objective measure of unmet need for in-patient services, but the considerable planned expansion of private beds, in the north-west for example, should be considered as a strong indication of significant unmet demand.

The NICAPS study has revealed a scarcity of emergency provision, which is striking, given that this is consistently reported as the foremost requirement of community CAMHS. Whatever the absolute bed numbers available, the shortage of emergency beds must contribute to the rates of inappropriate admission elsewhere. Cotgrove (1997) reviewed the obstacles to providing emergency beds in small units and described one model of integrating emergency and treatment services; however, this integration was achieved at a cost to the therapeutic milieu and ward atmosphere. Corrigall \& Mitchell (2002) described a service focused principally on responding to emergencies, but again other aspects of a comprehensive tier 4 service appear to have been neglected.

\section{THE FUTURE OF IN-PATIENT CAMHS}

What does the future hold for in-patient services, and what can be done to improve the outlook? A good starting point would be to attempt to measure need. However, 
this is a complex task. It is extremely difficult to gauge absolute need for in-patient provision without taking the full range of other child and adolescent mental health services into account, including those provided by other agencies such as social services, education and youth justice. In addition, the presence of day units or specialist out-patient facilities, for example, might affect the demand for in-patient beds. Defining the purpose of in-patient facilities is also an essential part of quantifying need. It is generally accepted that in-patient facilities provide assessment and management of young people with severe or complex problems that cannot be managed in tier 3 CAMHS. Specific criteria, however, vary between units, for example concerning age range, the treatment of young people with learning disability and the relative priority given to treating emerging personality disorder. Even before such a needs assessment is completed, there is enough evidence to suggest that there is currently a significant shortfall in provision. While there is a good case to argue that we need more of all types of in-patient facilities, NICAPS specifically highlighted the lack of emergency access to beds and a lack of intensive support facilities (which they referred to as 'secure') within the NHS. We suggest that these gaps should be addressed as a high priority by establishing specialist units to complement rather than replace existing hard-pressed services. There is an opportunity to link such developments with newly emerging services for early intervention in psychosis.

Currently youngsters with complex and severe mental health needs combined with social care and/or educational needs can get a poor deal. Once picked up by one agency, there may then be difficulties in accessing services from another. We suggest that models of service provision be developed that allow for high levels of cooperation and joint planning between agencies. Workforce planning is vital and should take into account the training needs of an expanding workforce across CAMHS. Staffing levels of in-patient services should reflect the training role they currently fulfil and allow for the regular movement of staff into community services.

One of the greatest impediments to the development of comprehensive and coherent services to meet the needs of service users and referrers has been the piecemeal way in which in-patient services have

SIMON G. GOWERS, FRCPsych, University of Liverpool Section of Adolescent Psychiatry; ANDREW COTGROVE, MRCPsych, Pine Lodge Young People's Centre, Chester, UK

Correspondence: Professor Simon Gowers, University of Liverpool Section of Adolescent Psychiatry, Academic Unit, 79 Liverpool Road, Chester $\mathrm{CH} 2$ IAW, UK

(First received 3 April 2003, accepted 16 June 2003)

historically been commissioned. The establishment of commissioning by primary care trusts may worsen the situation owing to the relatively small geographical catchment areas that they cover and the increased potential for competition for resources with tier 3 and other CAMHS. Worthy documents pertaining to the provision of CAMHS such as Together We Stand (Health Advisory Service, 1995) make no reference to the capacity of tier 4 services to guide commissioners. Guidelines published by the Royal College of Psychiatrists (1992) suggesting 24-40 child and adolescent mental health beds per million of general population are generally ignored. We strongly endorse the suggestion that national planning is needed for in-patient services. In addition to addressing the scope of such facilities, targets are needed regarding capacity for a given population. We eagerly await the forthcoming publication of the Children's National Service Framework and hope that this document will address some of the above issues; a lack of recommendations regarding in-patient capacity targets may, however, be an opportunity missed.

\section{SUMMARY OF \\ RECOMMENDATIONS}

A national plan for in-patient child and adolescent mental health services is needed. It should include the following recommendations:

(a) a full needs assessment for in-patient CAMHS should be performed to inform proposals on the range and capacity of services;

(b) gaps in current provision such as emergency access to specialist beds and intensive support facilities should be addressed as a priority;

(c) closer working between the Departments of Health, social services, education and youth justice is required to meet the needs of youngsters with complex problems; (d) workforce planning and training is needed to provide the staff for an expansion in services;

(e) commissioning should be organised for a larger geographical area than that covered by individual primary care trusts;

(f) further research is needed to provide an evidence base for different models of service provision.

\section{DECLARATION OF INTEREST}

None.

\section{REFERENCES}

Corrigall, R. \& Mitchell, B. (2002) Service innovations: rethinking in-patient provision for adolescents. A report from a new service. Psychiatric Bulletin, 26, 388-392.

Cotgrove, A. (1997) Emergency admissions to a regional adolescent unit: piloting a new service. Psychiatric Bulletin, 21, 604-608.

Duthie, P. (200I) In-patient adolescent services (letter) Psychiatric Bulletin, 25, 360 .

Gowers, S., Symington, R. \& Entwistle, K. (1991)

Who needs an adolescent unit? A referrer satisfaction study. Psychiatric Bulletin, I5, 537-540.

_, Clarke, J., Alldis, M., et al (200I) Inpatient admission of adolescents with mental disorder. Clinical Child Psychology and Psychiatry, 6, 537-544.

Health Advisory Service (1995) Child and Adolescent Mental Health Services: Together We Stand. London: HMSO.

O'Herlihy, A., Worrall, A., Banerjee, S., et al (200I) National In-Patient Child and Adolescent Psychiatry Study (NICAPS). Final Report to the Department of Health London: Royal College of Psychiatrists' Research Unit.

Lelliott, P., et al (2003) Distribution and characteristics of in-patient child and adolescent mental health services in England and Wales. British Journal of Psychiatry, 183, 547-55।.

Royal College of Psychiatrists (1992) Mental Health of the Nation. The Contribution of Psychiatry (Council Report CRI6). London: Royal College of Psychiatrists.

- (2002) Acute In-Patient Psychiatric Care for Young People with Severe Mental Illness. Recommendations for Commissioners, Child and Adolescent Psychiatrists and General Psychiatrists (Council Report CRI06). London: Royal College of Psychiatrists. 